\title{
Diffuse fluorodeoxyglucose-positron uptake in the bone marrow of a patient with granulocyte colony-stimulating factor-producing pleomorphic carcinoma of the lung: A case report
}

\author{
TAKASHI MAKINO ${ }^{1}$, YOSHINOBU HATA ${ }^{1}$, HAJIME OTSUKA ${ }^{1}$, SATOSHI KOEZUKA ${ }^{1}$, NAO KIKUCHI ${ }^{2}$, \\ KAZUTOSHI ISOBE $^{2}$, NAOBUMI TOCHIGI ${ }^{3}$, KAZUTOSHI SHIBUYA $^{3}$, SAKAE HOMMA $^{2}$ and AKIRA IYODA ${ }^{1}$ \\ Divisions of ${ }^{1}$ Chest Surgery and ${ }^{2}$ Respiratory Medicine; ${ }^{3}$ Department of Surgical Pathology, \\ Toho University School of Medicine, Tokyo 143-8541, Japan
}

Received April 12, 2016; Accepted February 16, 2017

DOI: $10.3892 / \mathrm{mco} .2017 .1271$

\begin{abstract}
The current study presents the case of a 66-year-old male presenting with fever and chest pain. Chest enhanced computed tomography scanning revealed a mass shadow in the right upper lobe with chest wall invasion. 18-Fluorodeoxyglucose-positron emission tomography (FDG-PET) identified the localized uptake of the mass lesion in the right upper lobe, in addition to diffuse uptake by the bone marrow. The laboratory data on admission revealed marked leukocytosis and an elevated C-reactive protein level (CRP). Serum concentrations of granulocyte colony-stimulating factor (G-CSF) and interleukin 6 were increased. Based on a clinical diagnosis of non-small cell lung cancer (c-T3NOM0 stage IIB), the patient underwent right upper lobectomy with chest wall resection. The histological examination showed a pulmonary pleomorphic carcinoma. Immunohistochemical analysis of the resected tumor tissues revealed positive staining for G-CSF. The patient's high-grade fever, leukocytosis, and elevated CRP level rapidly subsided following the resection. This confirmed that the tumor was a G-CSF-producing pulmonary pleomorphic carcinoma. Five months after the resection, the diffuse FDG uptake in the bone marrow was absent, even with the presence of a small pulmonary metastasis and marginal serum G-CSF elevation. Diffuse FDG uptake in bone marrow induced by G-CSF producing pleomorphic carcinoma must be taken
\end{abstract}

Correspondence to: Professor Akira Iyoda, Division of Chest Surgery, Toho University School of Medicine, 6-11-1 Omori-nishi, Ota-ku, Tokyo 143-8541, Japan

E-mail: aiyoda@med.toho-u.ac.jp

Abbreviations: FDG-PET, 18-Fluorodeoxyglucose-positron emission tomography; CRP, C-reactive protein; G-CSF, granulocyte colony-stimulating factor; NSCLC, non-small cell lung cancer; IL-6, interleukin 6; CT, computed tomography

Key words: FDG-PET, pleomorphic carcinoma, G-CSF, lung cancer, surgery into consideration, in order for it not to be misinterpreted as diffuse bone marrow metastases or hematologic malignancy.

\section{Introduction}

There have been several previous studies reporting that various cytokines, including granulocyte colony-stimulating factor (G-CSF) and interleukin 6 (IL-6), are produced by lung carcinomas, particularly pleomorphic carcinomas previously diagnosed as large cell carcinomas (1-7). G-CSF production by cancer cells has been associated with the rapid progression of the disease and with the poor prognosis.

Pleomorphic carcinoma of lung was first classified in 1999 by the World Health Organization as a subset of sarcomatoid carcinoma. This type of tumor is rare, accounting for $2-3 \%$ of all cancer cases in a previous surgical series, but for $<1 \%$ in epidemiological studies (8). Pleomorphic carcinoma is a poorly-differentiated non-small cell lung carcinoma, which may consist of a squamous cell carcinoma, adenocarcinoma or undifferentiated non-small cell carcinoma that contains $\geq 10 \%$ spindle and/or giant cells or a carcinoma consisting only of spindle and giant cells. Pleomorphic carcinoma of the lung has been reported to have aggressive clinical course with a poor response to chemotherapy and radiotherapy (8). The prognosis is significantly poorer than that of most other subsets of non-small cell lung cancer, even in early-stage disease.

G-CSF causes hypermetabolic uptake of bone marrow in positron emission tomography (PET) using F-18-fluorodeoxyglucose (FDG) $(9,10)$. The current case encountered diffuse FDG uptake in the bone marrow by G-CSF-producing pleomorphic carcinoma prior to the tumor resection, and this uptake was considered to have occurred due to the amount of G-CSF present.

\section{Case report}

A 66-year-old male presenting with high-grade fever and chest pain was admitted to Toho University Omori medical center (Tokyo, Japan) in November, 2013. Chest computed tomography $(\mathrm{CT})$ revealed a $6-\mathrm{cm}$ mass in the right upper lobe (Fig. 1A), invading the chest wall. Laboratory testing identified 

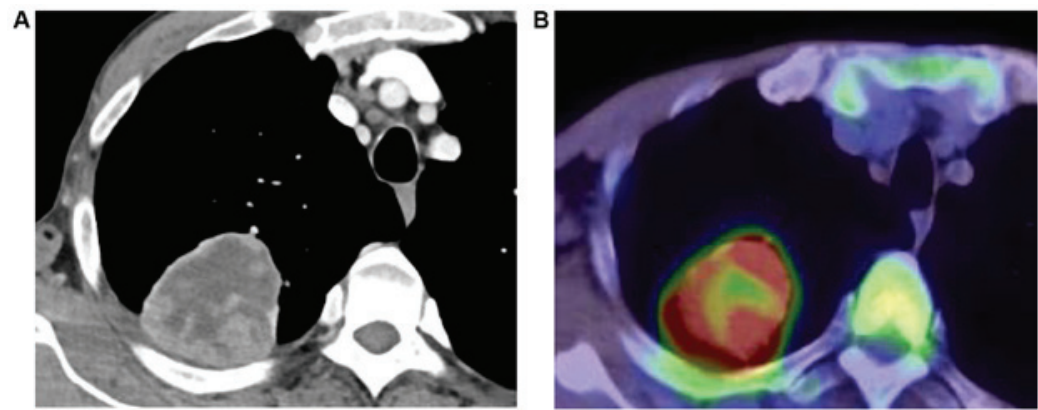

Figure 1. (A) Chest CT scan revealing a 6-cm mass in the right upper lobe, invading the chest wall. (B) Positron emission tomography/CT scan showing the localized uptake of the mass lesion in the right upper lobe. CT, computed tomography.
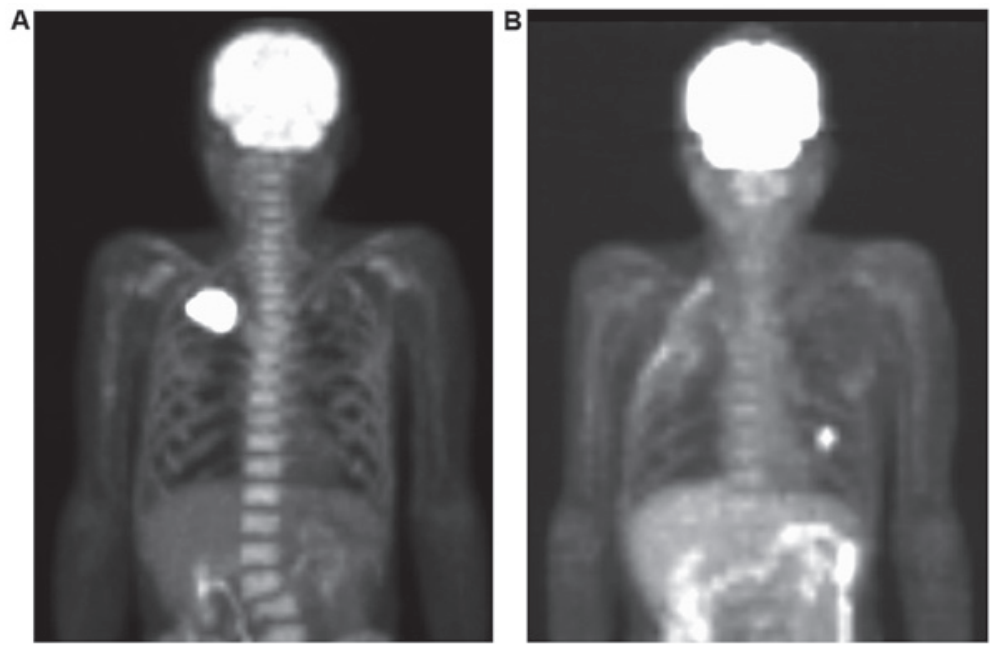

Figure 2. (A) FDG-PET showing the localized uptake of the mass lesion in the right upper lobe, in addition to diffuse uptake by the bone marrow. (B) FDG-PET revealing that FDG uptake was localized to the nodule in the left lower lobe without diffuse uptake in the bone marrow 5 months after resection. FDG-PET, 18 Fluorodeoxyglucose-positron emission tomography.
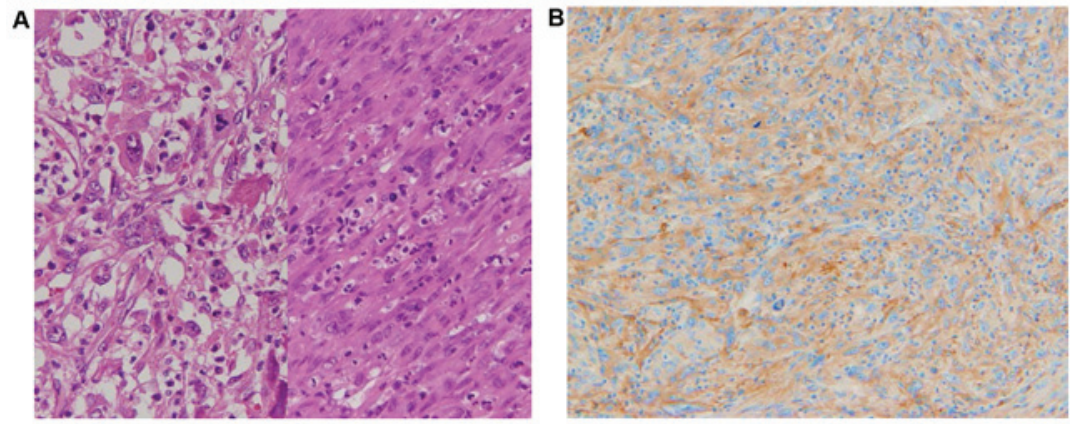

Figure 3. (A) Micrograph of the resected specimen revealing that the majority of the tumor was composed of giant cells (left) and spindle cells (right) surrounded by inflammatory cells. Staining, hematoxylin and eosin; magnification, x40. (B) Immunohistochemical analysis of the resected tumor tissues with granulocyte colony-stimulating factor antibody. The tumor cells were positive for G-CSF. Magnification, $\mathrm{x} 40$.

marked peripheral leukocytosis $\left(2.27 \times 10^{9} / 1\right)$ and an elevated C-reactive protein [CRP, $13.3 \mathrm{mg} / \mathrm{dl}$, normal range (NR), $<0.25 \mathrm{mg} / \mathrm{dl}]$. Serum concentrations of G-CSF and IL-6 were $203 \mathrm{pg} / \mathrm{ml}(\mathrm{NR}<39 \mathrm{pg} / \mathrm{ml})$ and $44.8 \mathrm{pg} / \mathrm{ml}(\mathrm{NR}<4.4 \mathrm{pg} / \mathrm{ml})$, respectively. 18 Fluorodeoxyglucose-positron emission tomography (FDG-PET) revealed the localized uptake of the mass lesion in the right upper lobe (Fig. 1B), and diffuse uptake in the bone marrow (Fig. 2). Hematological disease, including lymphoma and diffuse bone marrow metastases, was excluded.
The tumor cell was not identified by a bone-marrow aspiration. The biopsy samples revealed hyperplasia of the normal bone marrow, mainly granulocytes.

Histological examination of the transbronchial biopsy specimens for the right lung tumor revealed a non-small cell lung cancer (NSCLC). Based on a clinical diagnosis of NSCLC (c-T3NOM0 stage IIB), the patient underwent right upper lobectomy with chest wall resection, and a $6.8 \times 6.0 \mathrm{~cm}$ tumor was completely resected. 
Histological examination using hematoxylin and eosin staining revealed that the tumor was composed primarily of giant cells and spindle cell surrounded by inflammatory cells (Fig. 3A). The patient was diagnosed with a pulmonary pleomorphic carcinoma, pT3N0M0, stage IIB. Immunohistochemical analysis of the resected tumor tissues revealed positive staining for G-CSF (cat. no. ab9691; dilution, 1:100; Abcam, Cambridge, UK) (Fig. 3B). Tissue underwent heat-mediated antigen retrieval in sodium citrate buffer (pH 6.0). The primary antibody was used at $0.25 \mu \mathrm{g} / \mathrm{ml}$ and incubated with the sample at $4^{\circ} \mathrm{C}$ overnight. A horseradish peroxidase-labeled polymer detection system was used with a 3,3'-diaminobenzidine chromogen (I-VIEW DAB universal kit, Roche Tissue Diagnostics, Tokyo, Japan), according to the manufacturer's protocol. The patient's high-grade fever, leukocytosis and the elevated CRP level rapidly subsided following the resection. Therefore, it was confirmed that the tumor was a G-CSF-producing pulmonary pleomorphic carcinoma.

Following the surgical treatment, the patient received two courses of adjuvant chemotherapy with cisplatin plus $\mathrm{S}-1$. However, 5 months after the resection, CT revealed a metastatic pulmonary nodule in the left lower lobe. FDG-PET identified abnormal FDG uptake in the nodule without diffuse uptake in the bone marrow (Fig. 2). The serum concentration of G-CSF showed marginal elevation as 45.3 (NR $<39 \mathrm{pg} / \mathrm{ml})$. At the time of this report, 12 months after the resection, the patient had undergone chemotherapy and was alive with lung and brain metastases.

Written informed consent for the publication of this case report and associated images was obtained from the patient.

\section{Discussion}

Pleomorphic carcinoma of the lung is defined as a group of poorly-differentiated NSCLCs that contains a component of sarcoma or sarcoma-like elements and exhibits carcinomatous as well as spindle and/or giant cell components (11). Pleomorphic carcinoma of the lung is rare and accounts for $<1 \%$ of all lung malignancies (12). Several previous studies have reported that various cytokines, such as G-CSF and IL-6, were produced by lung carcinomas, particularly pleomorphic carcinomas previously diagnosed as large cell carcinomas (13). In the previous cases, the elevated IL-6 levels may have contributed to high-grade fever and increased CRP levels (14), and the increased serum G-CSF levels may have contributed to leukocy tosis and hematopoietic activation (15). The diagnostic criteria for CSF-producing tumors are as follows: i) Extreme leukocytosis, ii) elevated CSF activity, iii) decreased WBC count after resection and iv) proof of CSF production in the tumor (16). In the present case, all these criteria were fulfilled.

In FDG-PET, hypermetabolic activity of FDG following administration of G-CSF corresponds to hyperactive bone marrow, and lasts $\sim 1$ month $(9,10)$. This increased FDG uptake in normal bone marrow following G-CSF administration may be explained by increased bone marrow metabolism and cellularity due to G-CSF treatment. In the present case, the PET findings were due to bone marrow hyperplasia induced by G-CSF produced by pulmonary pleomorphic carcinoma, and the high uptake in the bone was absent in the FDG-PET scan 5 months after the tumor resection, even in the presence of small pulmonary metastasis and marginal serum G-CSF elevation. These characteristic imaging findings are due to the quantity of G-CSF, and are predicted to be useful for the diagnosis of G-CSF-producing tumors.

In conclusion, the current study reported a case of diffuse FDG uptake in the bone marrow of a patient with granulocyte colony-stimulating factor-producing pleomorphic carcinoma of the lung. Diffuse FDG uptake in bone marrow induced by G-CSF producing pleomorphic carcinoma must be taken into consideration, in order for it not to be misinterpreted as diffuse bone marrow metastases or hematologic malignancy.

\section{Acknowledgements}

The present study was supported in part by Grants-in-aid for Scientific Research (C) (grant nos. 15K10272 and 26462140) from the Japanese Ministry of Education, Culture, Sports, Science and Technology.

\section{References}

1. Sekido Y, Sato M, Usami N, Shigemitsu K, Mori S, Maeda O, Yokoi T, Hasegawa Y, Yoshioka H and Shimokata K: Establishment of a large cell lung cancer cell line (Y-ML-1B) producing granulocyte colony-stimulating factor. Cancer Genet Cytogenet 137: 33-42, 2002.

2. Inoue M, Minami M, Fujii Y, Matsuda H, Shirakura R and Kido T: Granulocyte colony-stimulating factor and interleukin-6-producing lung cancer cell line, LCAM. J Surg Oncol 64: 347-350, 1997.

3. Katsumata N, Eguchi K, Fukuda M, Yamamoto N, Ohe Y, Oshita F, Tamura T, Shinkai T and Saijo N: Serum levels of cytokines in patients with untreated primary lung cancer. Clin Cancer Res 2: 553-559, 1996.

4. Tsuyuoka R, Takahashi T, Sasaki Y, Taniguchi Y, Fukumoto M, Suzuki A, Nakamura K, Kobayashi S, Kudo T and Nakao K: Colony-stimulating factor-producing tumours: Production of granulocyte colony-stimulating factor and interleukin-6 is secondary to interleukin-1 production. Eur J Cancer 30A: 2130-2136, 1994

5. Kimura H, Yamaguchi Y, Sun L, Iwagami S and Sugita K: Establishment of large cell lung cancer cell lines secreting hematopoietic factors inducing leukocytosis and thrombocytosis. Jpn J Clin Oncol 22: 313-319, 1992.

6. Matsuguchi T, Okamura S, Kawasaki C, Shimoda K, Omori F, Hayashi S, Kimura N and Niho Y: Constitutive production of granulocyte colony-stimulating factor and interleukin- 6 by a human lung cancer cell line, KSNY: Gene amplification and increased mRNA stability. Eur J Haematol 47: 128-133, 1991.

7. Suzuki A, Takahashi T, Okuno Y, Nakamura K, Tashiro H, Fukumoto M, Konaka Y and Imura H: Analysis of abnormal expression of g-csf gene in a novel tumor cell line (KHC 287) elaborating G-CSF, IL-1 and IL-6 with co-amplification of c-myc and c-ki-ras. Int J Cancer 48: 428-433, 1991.

8. Yendamuri S, Caty L, Pine M, Adem S, Bogner P, Miller A, Demmy TL, Groman A and Reid M: Outcomes of sarcomatoid carcinoma of the lung: A Surveillance, Epidemiology, and End Results Database analysis. Surgery 152: 397-402, 2012.

9. Sugawara Y, Fisher SJ, Zasadny KR, Kison PV, Baker LH and Wahl RL: Preclinical and clinical studies of bone marrow uptake of fluorine-1-fluorodeoxyglucose with or without granulocyte colony-stimulating factor during chemotherapy. J Clin Oncol 16: 173-180, 1998.

10. Kazama T, Swanston N, Podoloff DA and Macapinlac HA: Effect of colony-stimulating factor and conventional- or high-dose chemotherapy on FDG uptake in bone marrow. Eur J Nucl Med Mol Imaging 32: 1406-1411, 2005.

11. Brambilla E, Travis WD, Colby TV, Corrin B and Shimosato Y: The new World Health Organization classification of lung tumours. Eur Respir J 18: 1059-1068, 2001. 
12. Ito K, Oizumi S, Fukumoto S, Harada M, Ishida T, Fujita Y, Harada T, Kojima T, Yokouchi H and Nishimura M; Hokkaido Lung Cancer Clinical Study Group: Clinical characteristics of pleomorphic carcinoma of the lung. Lung Cancer 68: 204-210, 2010.

13. Fukuyama T, Ichiki Y, Yamada S, Shigematsu Y,Baba T, Nagata Y, Mizukami M, Sugaya M, Takenoyama M, Hanagiri T, et al: Cytokine production of lung cancer cell lines: Correlation between their production and the inflammatory/immunological responses both in vivo and in vitro. Cancer Sci 98: 1048-1054, 2007.

14. Guo Y, Xu F, Lu T, Duan Z and Zhang Z: Interleukin-6 signaling pathway in targeted therapy for cancer. Cancer Treat Rev 38: 904-910, 2012.

15. Mabuchi S, Morimoto A, Fujita M, Isohashi K and Kimura T: $\mathrm{G}-\mathrm{CSF}$ induces focal intense bone marrow FDG uptake mimicking multiple bone metastases from uterine cervical cancer: A case report and review of the literature. Eur J Gynaecol Oncol 33: 316-317, 2012.

16. Asano S, Urabe A, Okabe T, Sato N and Kondo Y: Demonstration of granulopoietic factor(s) in the plasma of nude mice transplanted with a human lung cancer and in the tumor tissue. Blood 49: 845-852, 1977. 